\title{
Mesenchymal stromal cells attenuate sevoflurane-induced apoptosis in human neuroglioma $\mathrm{H} 4$ cells
}

\author{
Yanyong Cheng ${ }^{\dagger}$, Yunfeng Jiang ${ }^{\dagger}$, Lei Zhang, Jiayi Wang, Dongdong Chai, Rong Hu, Chunzhu Li, Yu Sun * (D) \\ and Hong Jiang
}

\begin{abstract}
Background: Inhalation of sevoflurane can induce neuronal apoptosis, cognitive impairment and abnormal behaviors. Bone marrow mesenchymal stem cells (MSCs) can secret neurotrophic factors and cytokines to protect from oxidative stress-related neuronal apoptosis. However, whether MSCs can protect from sevoflurane-induced neuronal apoptosis and the potential mechanisms are unclear.
\end{abstract}

Methods: A non-contact co-culture of MSCs with human neuroglioma $\mathrm{H} 4$ cells ( $\mathrm{H} 4$ cells) was built. $\mathrm{H} 4$ cells were co-cultured with MSCs or without MSCs (control) for $24 \mathrm{~h}$. The co-cultured H4 cells were exposed to $4 \%$ sevoflurane for $6 \mathrm{~h}$. The levels of caspase-3, reactive oxygen species (ROS), adenosine triphosphate (ATP), and the release of cytochrome $\mathrm{C}$ were determined by Western blot and fluorescence assay.

Results: Sevoflurane exposure significantly elevated the levels of cleaved caspase 3 and Bax in $\mathrm{H} 4$ cells. However, these phenomena were significantly offset by the co-culture with MSCs in H4 cells. Co-culture with MSCs before, but not after, sevoflurane exposure, significantly attenuated sevoflurane-induced ROS production in H4 cells. MSCs prevented sevoflurane-mediated release of cytochrome C from the mitochondria and production of ATP in H4 cells.

Conclusions: Our study indicated that soluble factors secreted by MSCs attenuated the sevoflurane-induced oxidative stress and apoptosis of neuronal cells by preserving their mitochondrial function.

Keywords: Sevoflurane, Mesenchymal stem cells, Reactive oxygen species, Apoptosis, mitochondrial dysfunction

\section{Background}

Sevoflurane is an inhaled anesthetic for both adult and pediatric anesthesia frequently used in clinical practice, and has characteristics of low blood:gas coefficient, rapid onset and recovery. However, sevoflurane exposure can induce severe neurological side effects, such as cognitive impairment and abnormal behaviors, like autism spectrum disorder [1-5]. Our previous studies have shown that such adverse effects of sevoflurane may be associated with the dysfunction of the LIMK1-signaling pathway and downregulation of circulating insulin-like growth factor 1 in developing and aged rats [6,7]. Furthermore, sevoflurane

\footnotetext{
*Correspondence: dr_sunyu@163.com; dr_hongjiang@163.com

†Yanyong Cheng and Yunfeng Jiang contributed equally to this work.

Department of Anesthesiology, Shanghai Ninth People's Hospital Affiliated to

Shanghai Jiao Tong University School of Medicine, Center for Specialty

Strategy Research of Shanghai Jiao Tong University China Hospital

Development Institute, 639 Zhizaoju Road, Shanghai 200011, China
}

exposure is prone to development of cognitive dysfunction in rodents and monkeys $[3,8,9]$. Similarly, a prospective randomized parallel-group study shows that inhalation of sevoflurane can promote the progression of amnestic mild cognitive impairment [10]. Moreover, sevoflurane exposure can change neurocognitive development and brain structure, leading to an increased risk of cognitive dysfunction in pediatric patients $[2,11-13]$. However, the mechanisms underlying the neurotoxicity of sevoflurane against neuronal cells have not been clarified.

Sevoflurane can stimulate reactive oxygen species (ROS) production and induce neurodegeneration and synaptic loss, including mitochondria dysfunction [14, 15]. Indeed, antioxidant and inhibitors for nicotinamide adenine dinucleotide phosphate oxidase (NADPH) can protect against long-term memory impairment and neuronal apoptosis in rodents by reducing superoxide

(c) The Author(s). 2018 Open Access This article is distributed under the terms of the Creative Commons Attribution 4.0 International License (http://creativecommons.org/licenses/by/4.0/), which permits unrestricted use, distribution, and 
levels [16]. Hence, antioxidants and inhibition of ROS production can potentially inhibit sevoflurane-related neuronal toxicity.

Recent studies have demonstrated that mesenchymal stem cells (MSCs) can secrete neurotrophic factors, chemokines and cytokines, which have potent neuroprotective effects [17-20]. Infusion with MSCs improves ischemia reperfusion-induced neuronal injury in rodents $[21,22]$. Previous clinical trials have demonstrated that MSC-based therapies are safe and effective for some diseases [23, 24]. Accordingly, we hypothesize that soluble factors secreted by MSCs can protect from sevoflurane-induced oxidative stress and neuronal apoptosis by preserving the mitochondrial function.

Glial cells regulate the synapse development and neuronal dysfunction [25], such as Alexander disease that manifests leukodystrophy and intellectual disability. $\mathrm{Hu}-$ man neuroglioma $\mathrm{H} 4$ cells (H4 cells) share some similarities with glial cells in vitro and have been widely used for studies of neuronal impairment and apoptosis [26-28]. In this study, we employed a transwell-based co-culture system to determine the impact of soluble factors secreted by MSCs on sevoflurane exposure-induced ROS production, apoptosis and mitochondrial dysfunction in $\mathrm{H} 4$ cells in vitro.

\section{Methods}

\section{Cell cultures}

$\mathrm{H} 4$ cells were obtained from central laboratory of Shanghai Ninth People's Hospital Affiliated to Shanghai Jiao Tong University School of Medicine and cultured in Dulbecco's modified eagle medium (DMEM, $4.5 \mathrm{~g} / \mathrm{L}$ glucose, Hyclone, USA) containing $10 \%$ fetal bovine serum (FBS, Gibco, USA), 100 Units/ml penicillin and $100 \mu \mathrm{g} / \mathrm{ml}$ streptomycin (Gibco, USA). Bone marrow-derived MSCs were isolated from newborn male Sprague-Dawley rats (SD rats) (6-7 days). Briefly, $\mathrm{SD}$ rats were sacrificed and their femurs were dissected, followed by flushing with DMEM $(1 \mathrm{~g} / \mathrm{L}$ glucose). The isolated MSCs were cultured onto $10-\mathrm{cm}$ plastic dish and exchanged with fresh medium every three days. The third passage of MSCs was used for the co-culture system.

\section{Treatment with MSCs before sevoflurane exposure in $\mathrm{H} 4$ cells}

The effect of pretreatment with MSCs on the production of ROS and apoptosis of $\mathrm{H} 4$ cells was determined by a non-contact co-culture system. MSCs $\left(1 \times 10^{4}\right.$ cells/well, an optimal number determined by preliminary study) were cultured in DMEM (1 g/L glucose) in the upper chambers $(6.5 \mathrm{~mm}$ inserter, $0.4 \mu \mathrm{m}$ Polycarbonate Membrane, Costar, USA) while $\mathrm{H} 4$ cells $\left(1 \times 10^{5}\right.$ cells/well $)$ were cultured in DMEM (4.5 g/L glucose) in the bottom chambers at $37{ }^{\circ} \mathrm{C}$ in an incubator containing $21 \% \mathrm{O}_{2}$ and $5 \% \mathrm{CO}_{2}$ for $24 \mathrm{~h}$. The upper chambers of the $\mathrm{H} 4$ cells without MSCs pretreatment group were filled with DMEM (1 g/L glucose) only and served as the control. After the co-culture with MSCs, the upper chambers were removed and the culture medium was changed with new medium. The $\mathrm{H} 4$ cells in the bottom chambers were exposed to $4 \%$ Sevoflurane or in an incubator for $6 \mathrm{~h}$. The levels of intracellular ROS and apoptosis in H4 cells were detected at 0 and 24 h post sevoflurane exposure. Furthermore, the levels of ROS and apoptosis of $\mathrm{H} 4$ cells co-cultured with or without MSC pretreatment were also detected.

To investigate whether the neurotoxicity of sevoflurane was caused by oxidant stress effect, H4 cells cultured in the presence of oxidants (Rosup, $100 \mu \mathrm{M}$, Beyotime) was regarded as a positive control group; Antioxidant $\mathrm{N}$-acetylcysteine (NAC) (1 mM, Beyotime, China) was used to attenuate the sevoflurane-induced ROS level and apoptosis level. The experimental protocol is illustrated in Fig. 1.

\section{Treatment with MSCs after sevoflurane exposure in $\mathrm{H} 4$ cells}

$\mathrm{H} 4$ cells were cultured alone for $24 \mathrm{~h}$ and exposed to $4 \%$ sevoflurane for $6 \mathrm{~h}$. Subsequently, the H4 cells were cultured alone or co-cultured with MSCs for $24 \mathrm{~h}$. The levels of intracellular ROS in the different groups of cells were determined by fluorescent microscopy and spectrum.

\section{Detection of ROS generation}

The contents of ROS in $\mathrm{H} 4$ cells were determined by fluorescent microscopy and spectrum. Briefly, the harvested $\mathrm{H} 4$ cells were treated with $10 \mathrm{mM}$ 2,7-dichlorofluorescein diacetate (DCFH-DA) at $37{ }^{\circ} \mathrm{C}$ for $30 \mathrm{~min}$ and after being washed, the fluorescent signals in the different groups of $\mathrm{H} 4$ cells were observed under a fluorescent microscope (Ti-S, Nikon, Japan). In addition, the contents of fluorescent signals in the H4 cells were determined using a fluorometric microplate reader (Synergy $\mathrm{H1}$, BioTek, USA) at $488 \mathrm{~nm}$.

\section{Western blotting}

The different groups of $\mathrm{H} 4$ cells were lyzed in cell lysis buffer. After being centrifuged, the concentrations of total proteins in cell lysates were determined by bicinchoninic acid assay. The cells lysates (30 $\mu \mathrm{g} /$ lane) were separated by sodium dodecyl sulfate polyacrylamide gel electrophoresis on $10 \%$ or $12 \%$ gels and transferred onto polyvinylidene difluoride membranes. The membranes were blocked with 5\% fat-free dry milk in TBST and incubated with primary antibodies against caspase-3 (1:1000 dilution, Cell Signaling Technology \#9661, 


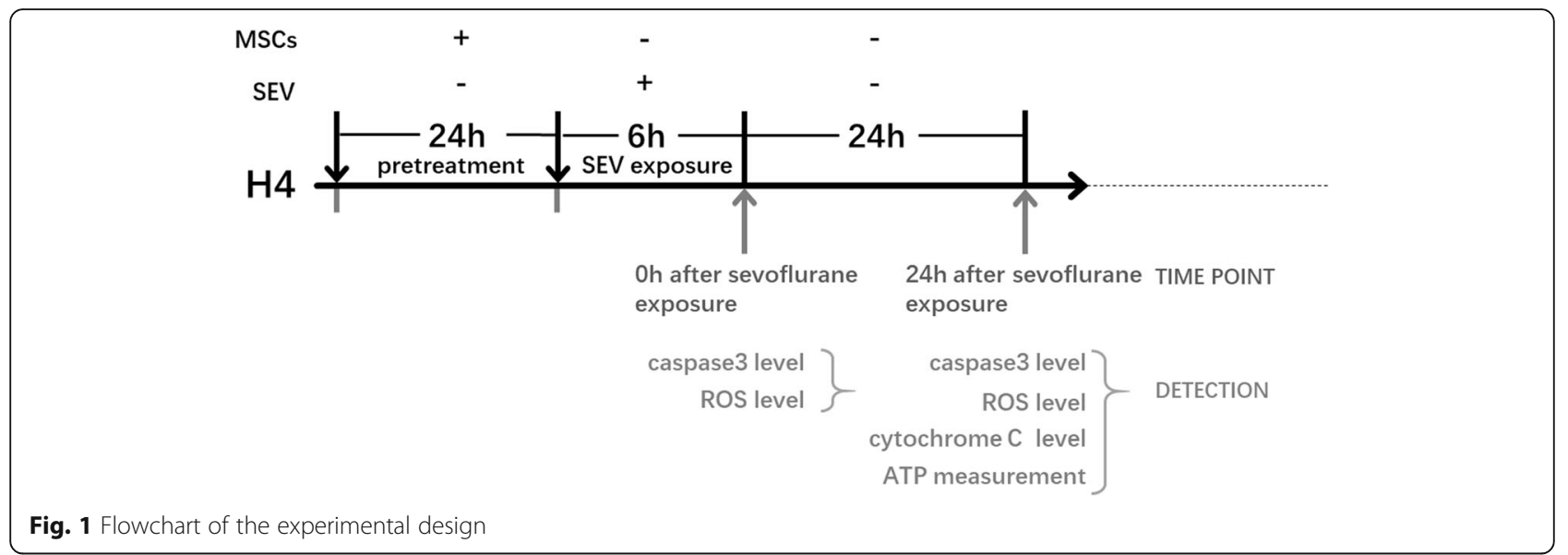

Danvers, MA), Bax (1:1000 dilution, Cell Signaling Technology \#2774, Danvers, MA), cytochrome C (1:1000 dilution, Cell Signaling Technology \#11940, Danvers, MA), Cox4 (1:1000 dilution, Cell Signaling Technology \#4850, Danvers, MA) and $\beta$-actin (1:1000 dilution, Cell Signaling Technology \#8457, Danvers, MA) at $4{ }^{\circ} \mathrm{C}$ overnight. The bound antibodies were detected with horseradish peroxidase-conjugated secondary anti-rabbit IgG (1:1000 dilution, Cell Signaling Technology \#7074, Danvers, MA) and visualized using the enhanced chemiluminescence (ECL, Thermo Fisher, USA). The relative levels of target protein to $\beta$-actin were determined by densitometric analysis using the Image J software.

In addition, the mitochondrial and cytosol samples were extracted from the different groups of $\mathrm{H} 4$ cells using the Cell Mitochondria Isolation Kit (Beyotime, China). The levels of cytochrome $\mathrm{C}$ in the mitochondria and cytosol samples were characterized by Western blot using Cox4 and $\beta$-actin as the internal references, respectively.

\section{Adenosine triphosphate (ATP) measurement}

The levels of ATP generated by the different groups of cells were determined by bioluminescent assay using the ATP Determination Kit (Invitrogen, USA), according to the manufacturer's instruction. Briefly, the different groups of H4 cells were cultured in transwell system overnight and exposed to sevoflurane, followed by culturing for another $24 \mathrm{~h}$. The H4 cells were harvested and lyzed in cold lysis buffer $(100 \mu \mathrm{l} /$ well), followed by centrifuging. The lysate samples were reacted in triplicate in $100 \mu \mathrm{l}$ of the standard reaction solution prepared freshly with reagents provided for $15 \mathrm{~min}$ and the luminescence (arbitrary unit) of individual wells was measured at emission of $560 \mathrm{~nm}$ in a luminometer (Synergy H1, BioTek, USA). The levels of ATP in individual samples were calculated, according to the standard curve established using different concentrations of ATP provided.

\section{Statistical analysis}

Data were expressed as mean \pm SD from each group $(n$ $=6$ per group). Differences among groups were statistically analyzed by one-way ANOVA and post hoc Fisher's least significant difference (LSD) using the Prism 5 Software. A $p$-value of less than 0.05 was considered statistically significant.

\section{Results}

MSCs mitigate $\mathrm{H} 4$ cell apoptosis induced by sevoflurane

We first tested the impact of MSC treatment on the sevoflurane-induced apoptosis in $\mathrm{H} 4$ cells by analysis of the relative levels of cleaved caspase $3(281.2 \pm 14.93 \%$ and $308.0 \pm 18.60 \%$ vs. $107.5 \pm 7.5 \%$ at 0 and $24 \mathrm{~h}$, respectively) and $\operatorname{Bax}(214.0 \pm 12.90 \%$ and $214.0 \pm 12.91 \%$ vs. $94.3 \pm 2.84 \%$ at 0 and $24 \mathrm{~h}$, respectively) in $\mathrm{H} 4$ cells without co-cultured with MSCs (Fig. 2). In contrast, co-cultured of $\mathrm{H} 4$ cells with MSCs significantly mitigated the sevoflurane-elevated cleaved caspase 3 (189.1 $\pm 9.30 \%$ vs. $281.2 \pm 14.93 \%, p<0.05$; and $179.0 \pm 8.49 \%$ vs. $308.0 \pm 18.60 \%, \mathrm{p}<0.05)$ and Bax immediately ( $0 \mathrm{~h}$, $105.0 \pm 2.36 \%$ vs. $214.0 \pm 12.90 \%, p<0.01)$ and $24 \mathrm{~h}$ $(105.4 \pm 2.36 \%$ vs. $214.0 \pm 12.91 \%, \mathrm{p}<0.01)$ after sevoflurane exposure in $\mathrm{H} 4$ cells in our experimental system (Fig. 2b and c).

\section{MSCs attenuate sevoflurane-induced ROS production in H4 cells}

Next, we measured the levels of intracellular ROS in $\mathrm{H} 4$ cells by DCFH-DA based fluorescent microscopy and spectrum. First, exposure to sevoflurane significantly increased the levels of cytoplasmic ROS at both immediately $(145.0 \pm 6.31 \%$ vs. $98.2 \pm 3.24 \%)$ and further $24 \mathrm{~h}$ culture $(132.4 \pm 4.13 \%$ vs. $98.2 \pm 3.24 \%)$ after sevoflurane exposure while co-culture with MSCs almost abrogated the sevoflurane-induced ROS production in $\mathrm{H} 4$ cells $(110.4 \pm 4.90 \%$ vs. $145.0 \pm 6.31 \% p<0.05$, or $106.9 \pm 3.45 \%$ vs. $132.4 \pm 4.13 \% p<0.01$, Fig. $3 \mathrm{a}$ and b). Similarly, 


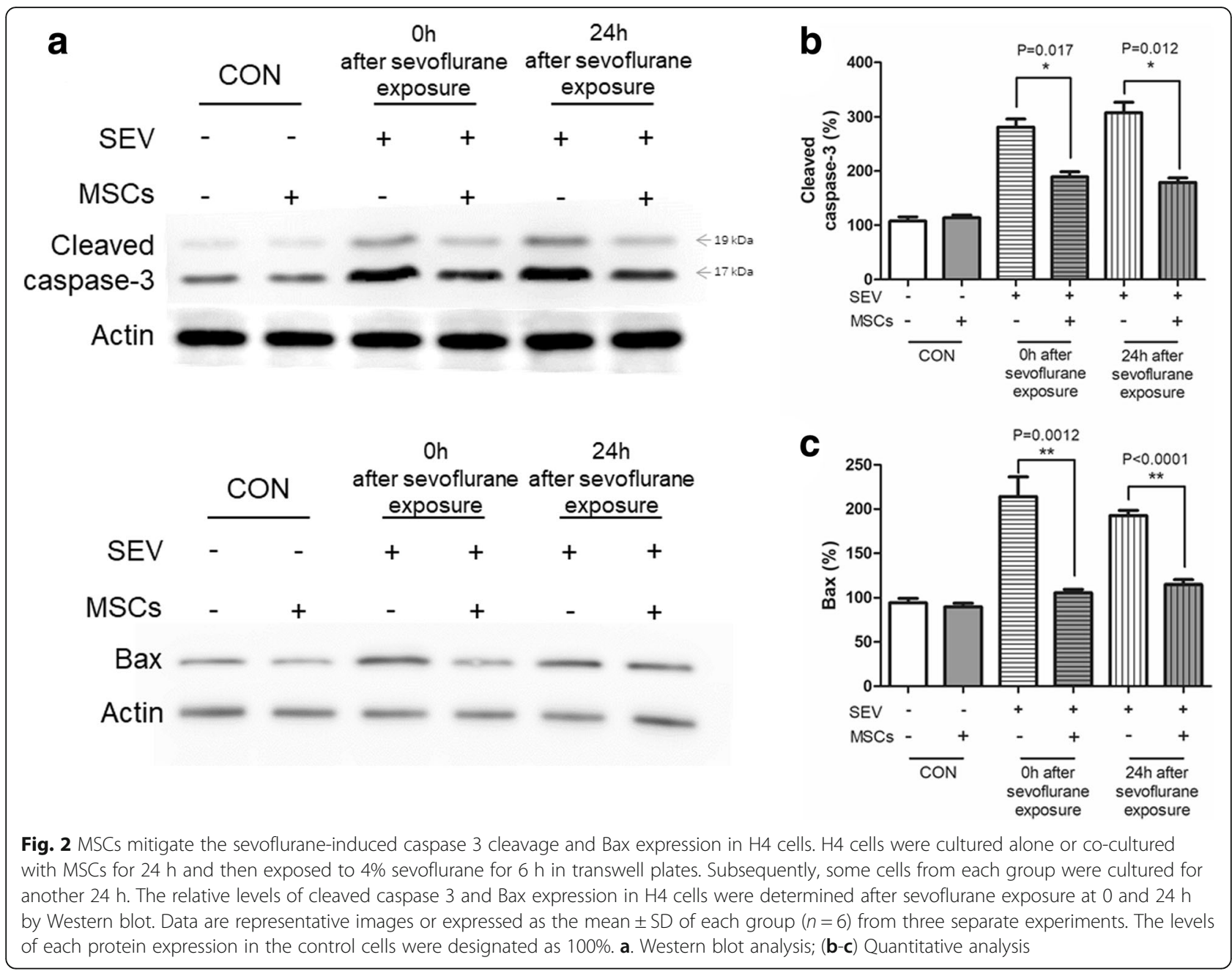

treatment with oxidant $(152.4 \pm 6.07 \%)$ induced high levels of ROS production while treatment with NAC (113.1 \pm $3.22 \%)$ to scavenge ROS dramatically attenuated the sevoflurane-induced ROS production in $\mathrm{H} 4$ cells $(p<0.01$ for all, Fig. 3c and d).

\section{Sevoflurane-induced apoptosis was attenuated by NAC}

We further investigated whether treatment with NAC could modulate the sevoflurane-induced apoptosis of $\mathrm{H} 4$ cells by measuring the relative levels of cleaved caspase 3 in the different groups of $\mathrm{H} 4$ cells by Western blot. We found that treatment with oxidant, like with sevoflurane (221.7 \pm $4.40 \%)$, significantly increased the levels of cleaved caspase $3(224.6 \pm 3.92 \%$ vs. $106.2 \pm 3.17 \%)$. However, treatment with MSCs or NAC significantly decreased the relative levels of cleaved caspase 3 in the sevoflurane-exposed $\mathrm{H} 4$ cells $(162.5 \pm 5.64 \%$ vs. $224.6 \pm 3.92 \%, p=0.008 ; 111.9 \pm$ $3.55 \%$ vs. $224.6 \pm 3.92 \%, p<0.001$ Fig. 4 ).

MSCs reduce the sevoflurane-mediated release of cytochrome $\mathrm{C}$ from the mitochondria of $\mathrm{H4}$ cells
High levels of ROS usually induce cell apoptosis through the mitochondrial pathway. During the process, apoptosis triggers can result in the loss of the mitochondrial transmembrane potential and release of cytochrome $\mathrm{C}$ in cells. To understand the action of sevoflurane-mediated apoptosis, we characterized the distribution of cytochrome $\mathrm{C}$ and ATP levels in $\mathrm{H} 4$ cells. We found that exposure to sevoflurane significantly decreased the levels of mitochondrial cytochrome C $(64.47 \pm 3.31 \%$ vs. $100.7 \pm 4.79 \%$, $p<0.01$ ), but increased the levels of cytosolic cytochrome C $(187.6 \pm 9.06 \%$ vs. $100.0 \pm 5.65 \%, p<0.01$, Fig. 5a-c). In contrast, co-culture with MSCs significantly restored the levels of mitochondrial cytochrome C $(85.5 \pm$ $3.95 \%$ vs. $64.47 \pm 3.31 \%, p<0.01)$ and mitigated the sevoflurane-increased cytosolic cytochrome $\mathrm{C}$ in $\mathrm{H} 4$ cells $(129.2 \pm 7.08 \%$ vs. $187.6 \pm 9.06 \%, p<0.01)$. Further analysis revealed that sevoflurane exposure significantly reduced the levels of ATP in H4 cells $(62.8 \pm 3.77 \%$ vs. $98.2 \pm$ $2.99 \%, \mathrm{p}<0.01)$ while co-culture with MSCs prevented the sevoflurane-decreased ATP levels in H4 cells (85.1 \pm $3.14 \%$ vs. $62.8 \pm 3.77 \% p<0.05$, Fig. 5 d). 


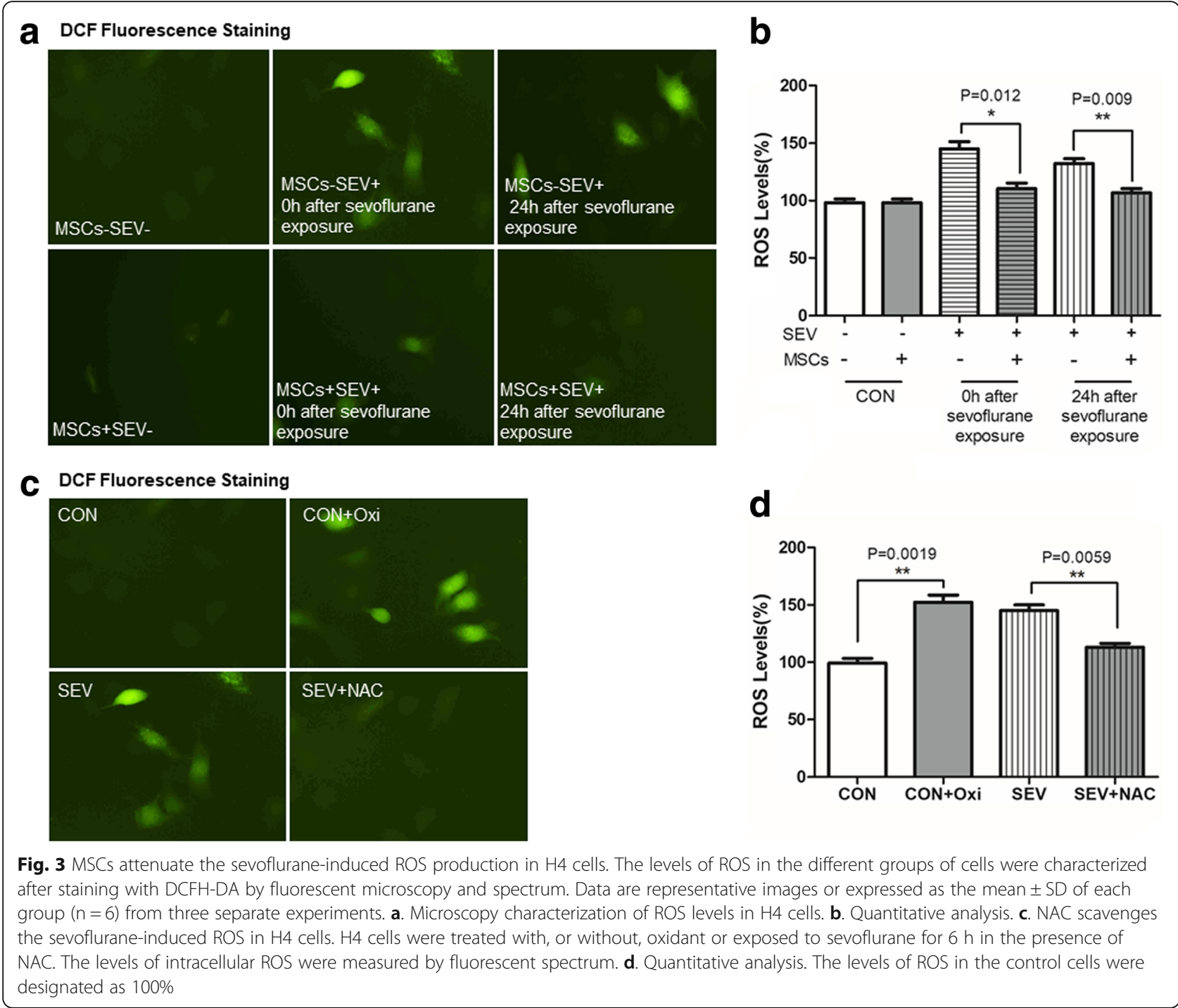

a

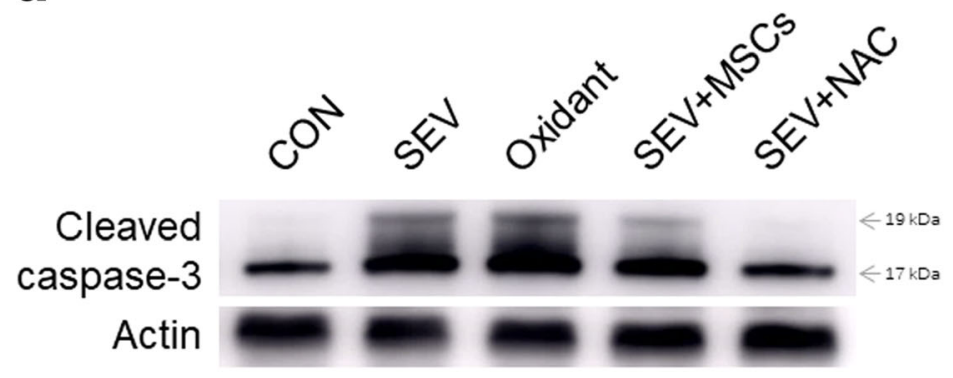

b

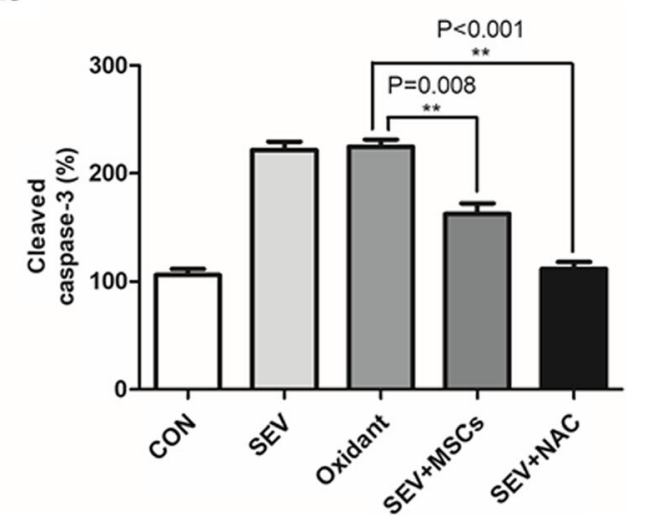

Fig. 4 NAC attenuates the sevoflurane-elevated caspase 3 cleavage in $\mathrm{H} 4$ cells. H4 cells were treated with vehicle (CON), SEV, Oxidant alone or together with MSCS (SEV + MSCs) or SEV + NAC. The relative levels of cleaved caspase 3 in the different groups of cells were determined by Western blot. Data are representative images or expressed as the mean \pm SD of each group $(n=6)$ from three separate experiments. a. Western blot analysis. b. Quantitative analysis. The levels of each protein expression in the control cells were designated as 100\% 


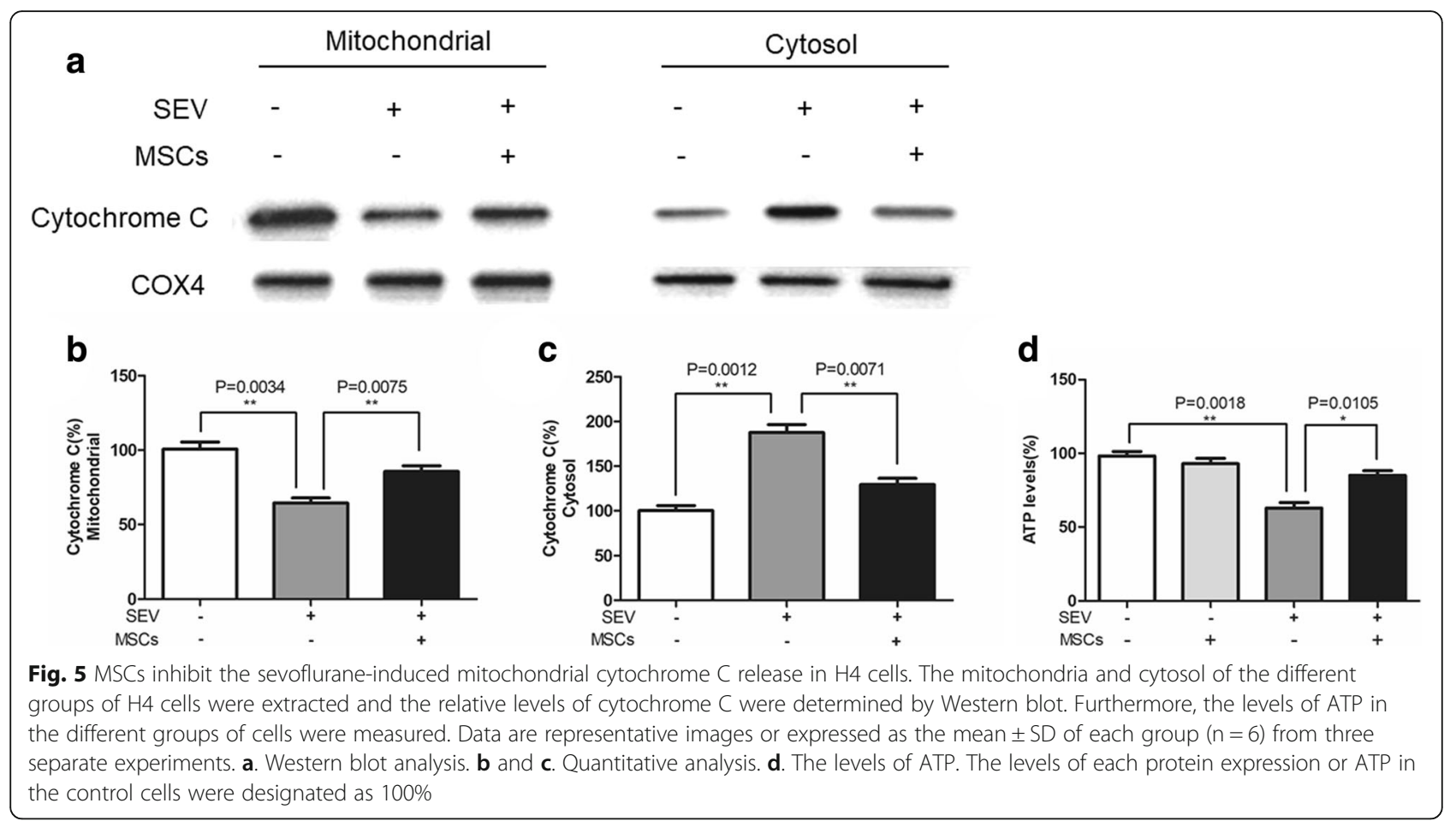

a DCF Fluorescence Staining
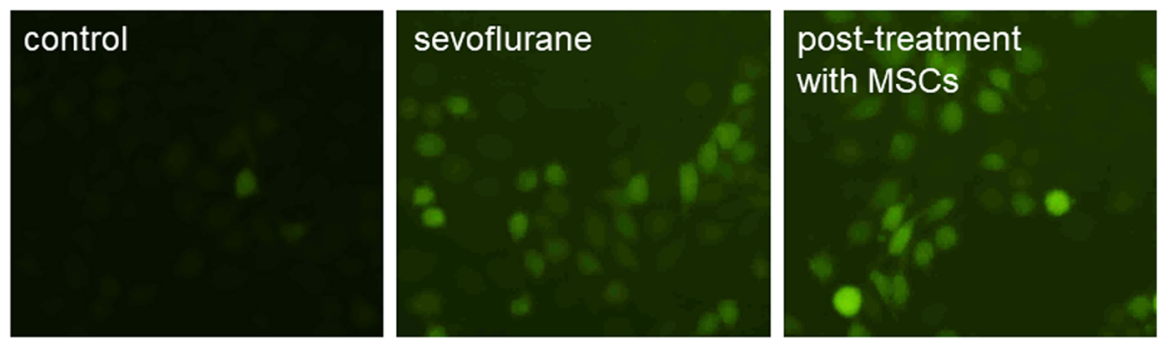

b

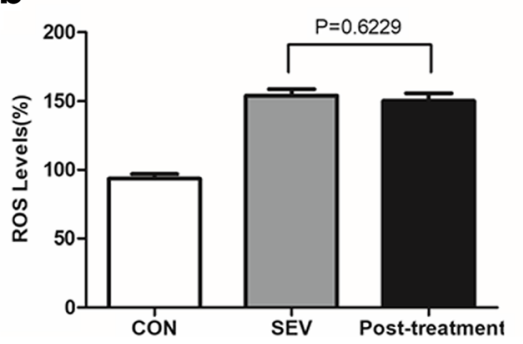

Fig. 6 Co-culture with MSCs after sevoflurane exposure does not alter the sevoflurane-induced ROS production in H4 cells. H4 cells were cultured for $24 \mathrm{~h}$ and exposed to sevoflurane, followed by co-cultured with MSCs or cultured alone for $24 \mathrm{~h}$. The control $\mathrm{H} 4 \mathrm{cells}$ were cultured alone throughout the experimental period. The cells were stained with DCFH-DA and the levels of ROS were determined by fluorescent microscopy and spectrum. Data are representative images or expressed as the mean \pm SD of each group $(n=6)$ from three separate experiments. $\mathbf{a}$. Fluorescent microscopy analysis of ROS in $\mathrm{H} 4$ cells. $\mathbf{b}$. Fluorescent spectrum analysis of the ROS levels in $\mathrm{H} 4$ cells. The levels of ROS in the control cells were designated as $100 \%$ 


\section{MSCs fail to inhibit the sevoflurane-induced ROS} production in $\mathrm{H} 4$ cells post sevoflurane exposure Finally, we tested whether treatment with MSCs post exposure to sevoflurane could inhibit the sevoflurane-induced ROS production in $\mathrm{H} 4$ cells. The levels of ROS were $93.7 \pm$ $3.28 \%$ (CON), $154.0 \pm 4.69 \%$ (SEV), $150.2 \pm 5.55 \%$ (Post-treatment), respectively. We found that sevoflurane exposure significantly induced high levels of ROS production $(154.0 \pm 4.69 \%$ vs. $93.7 \pm 3.28 \%)$ and co-culture with MSCs after sevoflurane exposure did not change the levels of sevoflurane-induced ROS production in H4 cells (150.2 \pm $5.55 \%$ vs. $154.0 \pm 4.69 \%, p>0.05$, Fig. 6 ).

\section{Discussion}

In this study, we found that treatment with MSCs before, but not after, sevoflurane exposure attenuated the sevoflurane-induced ROS production and apoptosis in H4 cells, which was abrogated by antioxidant NAC. MSCs prevented the sevoflurane-induced cytochrome $\mathrm{C}$ release from the mitochondria to the cytoplasm and ATP production in $\mathrm{H} 4$ cells. These novel data extended previous observations [17-22] and indicated that soluble factors secreted by MSCs had potent antioxidant activity against oxidative stress-induced apoptosis in $\mathrm{H} 4$ cells. These finding may provide new insights into the neuronal toxicity of sevoflurane. Given that sevoflurane is an inhaled anesthetic used widely in the clinical practice in anesthesia our findings suggest that we should be cautious while using sevoflurane.

MSCs can secrete neurotrophic factors, cytokines and other soluble factors that are associated neuroprotective activity [17-20]. In this study, while sevoflurane exposure induced ROS production, mitochondrial cytochrome $\mathrm{C}$ release and apoptosis in $\mathrm{H} 4$ cells co-culture with MSCs before sevoflurane exposure almost completely prevented the oxidant activity of sevoflurane in $\mathrm{H} 4$ cells. However, we found that co-culture with MSCs after sevoflurane exposure failed to mitigate the sevoflurane-induced ROS production in $\mathrm{H} 4$ cells. These data suggest that sevoflurane may trigger an oxidative cascade that induces the mitochondrial damages and apoptosis of $\mathrm{H} 4$ cells, which may not be easily overcome by soluble factors from MSCs [29]. A recent study has shown that infusion of MSCs improves symptoms in patients with Alzheimer's disease [30]. Further studies are necessary to identify soluble factors secreted by MSCs and determine the molecular mechanisms underlying the action of MSCs.

Given that this experiment was performed in transwell plates the antioxidant effect of MSCs was likely mediated by their soluble factors. Indeed, MSCs can secrete neurotrophic factors, cytokines and other extracellular vesicles (EVs). Our findings support the theory that the EVs secreted by MSCs are responsible for their immunosuppressive activity [31] and the neuronal protection by MSCs may be independent of cell-to-cell contact. It is notable that EVs include exosomes, ectosomes, microvesicles, microparticles, apoptotic bodies and other EV subsets [32]. We are interested in further investigating which type of EV(s) has such potent antioxidant activity and neuronal protective effect. Given that most EVs are able to pass through the blood-brain barrier and are relatively stable the identified EVs or soluble factors may be valuable for cell-free therapy of oxidative stress-related neuronal degenerative diseases.

We recognized that our study has limitations. First, the MSCs were extracted from newborn SD rats and tested in a human cell line. However, MSCs have the advantage of low-immunogenicity which make them potentially safe for clinical use. Because of MSC's immunomodulatory effects, they can be used to repair the damage caused by autoimmune-induced disease and graft-versus-host disease [33]. Autologous and allogenic bone marrow derived MSCs have been shown to be safe for human use [34, 35]. Xenogeneic bone marrow derived MSCs from human, mouse and rat have been widely used in animal experiments [3638]. Because of the role of MSC-derived EVs, EVs isolated from conditioned media of MSCs would be used in our further animal studies. Second, although we used an optimal dose of MSCs in our experiments we did not test the time course of the co-culture system in detail. Once MSCs and H4 cells were seeded into their own chambers respectively, the co-culture system was started. After culture for $24 \mathrm{~h}$, the cells should be in the best condition of density and the sevoflurane exposure started. Further studies are needed to test whether co-culture for varying time periods or culture for a longer period after exposure to sevoflurane has different effects on sevoflurane-induced apoptosis and ROS production because co-culture for $24 \mathrm{~h}$ or exposure to sevoflurane for $6 \mathrm{~h}$ may be not optimal. Third, these results were based on cell experiments and still need to be confirmed in animals.

\section{Conclusions}

Sevoflurane is the most widely used inhaled anesthetic in clinical practice. In this study, we demonstrated that the exposure to $4 \%$ sevoflurane for $6 \mathrm{~h}$ induced ROS production, apoptosis and caspase- 3 activation in H4 cells. Furthermore, we revealed that the sevoflurane-mediated apoptosis was mediated by the mitochondrial pathway. In addition, we found for the first time that the co-culture system with MSCs reduced the toxic effect of sevoflurane on $\mathrm{H} 4$ cells. Potentially, our findings may aid in design of new therapies for prevention of sevoflurane-induced neuronal damage.

\section{Abbreviations}

ATP: Adenosine triphosphate; DCFH-DA: 2,7-dichlorofluorescein diacetate; DMEM: Dulbecco's modified eagle medium; FBS: Fetal bovine serum; H4 
cells: Human neuroglioma H4 cells; MSCs: Mesenchymal stem cells; NAC: Nacetylcysteine; ROS: Reactive oxygen species; SD rats: Sprague-Dawley rats

\section{Acknowledgements}

We thank Medjaden for its linguistic assistance during the preparation of this manuscript.

\section{Funding}

This study was supported by the Department of Anesthesiology, Shanghai Ninth People's Hospital Affiliated to Shanghai Jiao Tong University School of Medicine.

\section{Availability of data and materials}

The datasets used and/or analyzed during the current study are available from the corresponding author on reasonable request.

\section{Authors' contributions}

YC carried out the studies and drafted the manuscript. YJ carried out the studies and prepared the manuscript. LZ conceived of the study and participated in its design and coordination. JW carried out the studies and collected the data. DC performed the statistical analysis. RH helped in designing the study. $\mathrm{CL}$ performed the statistical analysis. YS participated in the design of the study and coordination. HJ participated in the design of the study. All authors read and approved the final manuscript.

\section{Ethics approval and consent to participate}

All experimental protocols were approved by the Animal Care and Use of Shanghai Ninth People's Hospital Affiliated to Shanghai Jiao Tong University School of Medicine Committee.

\section{Consent for publication}

Not applicable.

\section{Competing interests}

The authors declare that they have no competing interests.

\section{Publisher's Note}

Springer Nature remains neutral with regard to jurisdictional claims in published maps and institutional affiliations.

Received: 26 December 2017 Accepted: 27 June 2018

\section{Published online: 18 July 2018}

\section{References}

1. Takaenoki Y, Satoh Y, Araki Y, Kodama M, Yonamine R, Yufune S, Kazama T. Neonatal exposure to sevoflurane in mice causes deficits in maternal behavior later in adulthood. Anesthesiology. 2014;120:403-15.

2. Shen X, Dong $Y, X u Z$, Wang H, Miao C, Soriano SG, Sun D, Baxter MG, Zhang $Y$, Xie Z. Selective anesthesia-induced neuroinflammation in developing mouse brain and cognitive impairment. Anesthesiology. 2013; 118:502-15.

3. Satomoto M, Satoh Y, Terui K, Miyao H, Takishima K, Ito M, Imaki J. Neonatal exposure to sevoflurane induces abnormal social behaviors and deficits in fear conditioning in mice. Anesthesiology. 2009;110:628-37.

4. Qiu J, Shi P, Mao W, Zhao Y, Liu W, Wang Y. Effect of apoptosis in neural stem cells treated with sevoflurane. BMC Anesthesiol. 2015;15:25.

5. Qiao $\mathrm{Y}$, Feng $\mathrm{H}$, Zhao $\mathrm{T}$, Yan $\mathrm{H}$, Zhang H, Zhao X. Postoperative cognitive dysfunction after inhalational anesthesia in elderly patients undergoing major surgery: the influence of anesthetic technique, cerebral injury and systemic inflammation. BMC Anesthesiol. 2015;15:154.

6. Yu Y, Zhang P, Yan J, Sun Y, Wu X, Xi S, Zhang L, Sun Y, Hu R, Jiang H. Sevoflurane induces cognitive impairments via the MiR-27b/LIMK1-signaling pathway in developing rats. Inhal Toxicol. 2016;28:731-8.

7. Jiang J, Lv X, Wu X, Yang Y, Jiang H. Downregulation of circulating insulinlike growth factor 1 contributes to memory impairment in aged mice after sevoflurane anesthesia. Behav Pharmacol. 2017;28:238-43.

8. Tao G, Zhang J, Zhang L, Dong Y, Yu B, Crosby G, Culley DJ, Zhang Y, Xie Z. Sevoflurane induces tau phosphorylation and glycogen synthase kinase 3beta activation in young mice. Anesthesiology. 2014;121:510-27.

9. Liu F, Rainosek SW, Frisch-Daiello JL, Patterson TA, Paule MG, Slikker W Jr, Wang C, Han X. Potential adverse effects of prolonged Sevoflurane exposure on developing monkey brain: from abnormal lipid metabolism to neuronal damage. Toxicol Sci. 2015;147:562-72.

10. Liu Y, Pan N, Ma Y, Zhang S, Guo W, Li H, Zhou J, Liu G, Gao M. Inhaled sevoflurane may promote progression of amnestic mild cognitive impairment: a prospective, randomized parallel-group study. Am J Med Sci. 2013;345:355-60.

11. Vutskits $L$, Xie Z. Lasting impact of general anaesthesia on the brain: mechanisms and relevance. Nat Rev Neurosci. 2016;17:705-17.

12. Backeljauw B, Holland SK, Altaye M, Loepke AW. Cognition and brain structure following early childhood surgery with anesthesia. Pediatrics. 2015; 136:e1-12.

13. Sun L. Early childhood general anaesthesia exposure and neurocognitive development. Br J Anaesth. 2010;105(Suppl 1):i61-8.

14. Boscolo A, Starr JA, Sanchez V, Lunardi N, DiGruccio MR, Ori C, Erisir A, Trimmer P, Bennett J, Jevtovic-Todorovic $V$. The abolishment of anesthesiainduced cognitive impairment by timely protection of mitochondria in the developing rat brain: the importance of free oxygen radicals and mitochondrial integrity. Neurobiol Dis. 2012;45:1031-41.

15. Liu B, Gu Y, Xiao H, Lei X, Liang W, Zhang J. Altered metabolomic profiles may be associated with sevoflurane-induced neurotoxicity in neonatal rats. Neurochem Res. 2015:40:788-99.

16. Sun Z, Satomoto M, Adachi Y, Kinoshita H, Makita K. Inhibiting NADPH oxidase protects against long-term memory impairment induced by neonatal sevoflurane exposure in mice. Br J Anaesth. 2016;117:80-6.

17. Caplan Al, Dennis JE. Mesenchymal stem cells as trophic mediators. J Cell Biochem. 2006;98:1076-84

18. Fu Y, Karbaat L, Wu L, Leijten J, Both SK, Karperien M. Trophic Effects of Mesenchymal Stem Cells in Tissue Regeneration. Tissue Eng Part B Rev. 2017;23:515-28.

19. Kim HS, Choi DY, Yun SJ, Choi SM, Kang JW, Jung JW, Hwang D, Kim KP, Kim DW. Proteomic analysis of microvesicles derived from human mesenchymal stem cells. J Proteome Res. 2012;11:839-49.

20. Koh SH, Noh MY, Cho GW, Kim KS, Kim SH. Erythropoietin increases the motility of human bone marrow-multipotent stromal cells (hBM-MSCs) and enhances the production of neurotrophic factors from hBM-MSCs. Stem Cells Dev. 2009;18:411-21.

21. Shen LH, Li Y, Chen J, Zacharek A, Gao Q, Kapke A, Lu M, Raginski K, Vanguri $P, S m i t h A$, et al. Therapeutic benefit of bone marrow stromal cells administered 1 month after stroke. J Cereb Blood Flow Metab. 2007;27:6-13.

22. Zhao MZ, Nonoguchi N, Ikeda N, Watanabe T, Furutama D, Miyazawa D, Funakoshi H, Kajimoto Y, Nakamura T, Dezawa M, et al. Novel therapeutic strategy for stroke in rats by bone marrow stromal cells and ex vivo HGF gene transfer with HSV-1 vector. J Cereb Blood Flow Metab. 2006;26:1176-88.

23. Bordignon C, Carlo-Stella C, Colombo MP, De Vincentiis A, Lanata L, Lemoli RM, Locatelli F, Olivieri A, Rondelli D, Zanon P, et al. Cell therapy: achievements and perspectives. Haematologica. 1999;84:1110-49.

24. Si YL, Zhao YL, Hao HJ, Fu XB, Han WD. MSCs: biological characteristics, clinical applications and their outstanding concerns. Ageing Res Rev. 2011; 10:93-103.

25. Pfrieger FW. Role of glial cells in the formation and maintenance of synapses. Brain Res Rev. 2010;63:39-46.

26. Cheng B, Zhang Y, Wang A, Dong Y, Xie Z. Vitamin C attenuates Isofluraneinduced Caspase-3 activation and cognitive impairment. Mol Neurobiol. 2015;52:1580-9.

27. Sun Y, Zhang Y, Cheng B, Dong Y, Pan C, Li T, Xie Z. Glucose may attenuate isoflurane-induced caspase-3 activation in $\mathrm{H} 4$ human neuroglioma cells. Anesth Analg. 2014;119:1373-80.

28. Zhang J, Dong Y, Xu Z, Zhang Y, Pan C, McAuliffe S, Ichinose F, Yue Y, Liang W, Xie Z. 2-Deoxy-D-glucose attenuates isoflurane-induced cytotoxicity in an in vitro cell culture model of $\mathrm{H} 4$ human neuroglioma cells. Anesth Analg. 2011;113:1468-75

29. Griendling KK, FitzGerald GA. Oxidative stress and cardiovascular injury: part I: basic mechanisms and in vivo monitoring of ROS. Circulation. 2003;108:1912-6.

30. de Windt T, Vonk L, Slaper-Cortenbach I, van den Broek M, Nizak R, van Rijen M, de Weger R, Dhert W, Saris D. Allogeneic Mesenchymal stem cells stimulate cartilage regeneration and are safe for single-stage cartilage repair in humans upon mixture with recycled autologous Chondrons. Stem Cells. 2017;35:256-64

31. Lai RC, Arslan F, Lee MM, Sze NS, Choo A, Chen TS, Salto-Tellez M, Timmers L, Lee CN, El Oakley RM, et al. Exosome secreted by MSC reduces myocardial ischemia/reperfusion injury. Stem Cell Res. 2010;4:214-22. 
32. Lotvall J, Hill AF, Hochberg F, Buzas El, Di Vizio D, Gardiner C, Gho YS, Kurochkin IV, Mathivanan S, Quesenberry P, et al. Minimal experimental requirements for definition of extracellular vesicles and their functions: a position statement from the International Society for Extracellular Vesicles. J Extracell Vesicles. 2014;3:26913.

33. Yang M, Liu L. MHC II gene knockout in tissue engineering may prevent immune rejection of transplants. Med Hypotheses. 2008;70:798-801.

34. Karussis D, Karageorgiou C, Vaknin-Dembinsky A, Gowda-Kurkalli B, Gomori JM, Kassis I, Bulte JW, Petrou P, Ben-Hur T, Abramsky O, et al. Safety and immunological effects of mesenchymal stem cell transplantation in patients with multiple sclerosis and amyotrophic lateral sclerosis. Arch Neurol. 2010; 67:1187-94.

35. Zhang H, Zeng X, Sun L. Allogenic bone-marrow-derived mesenchymal stem cells transplantation as a novel therapy for systemic lupus erythematosus. Expert Opin Biol Ther. 2010;10:701-9.

36. Costa-Ferro ZS, de Borba Cunha F, de Freitas Souza BS, Leal MM, da Silva AA, de Bellis Kuhn Tl, Forte A, Sekiya EJ, Soares MB, Dos Santos RR. Antiepileptic and neuroprotective effects of human umbilical cord blood mononuclear cells in a pilocarpine-induced epilepsy model. Cytotechnology. 2014;66:193-9.

37. Li T, Ren G, Kaplan DL, Boison D. Human mesenchymal stem cell grafts engineered to release adenosine reduce chronic seizures in a mouse model of CA3-selective epileptogenesis. Epilepsy Res. 2009;84:238-41.

38. Venturin GT, Greggio S, Marinowic DR, Zanirati G, Cammarota M, Machado DC, DaCosta JC. Bone marrow mononuclear cells reduce seizure frequency and improve cognitive outcome in chronic epileptic rats. Life Sci. 2011;89: 229-34

\section{Ready to submit your research? Choose BMC and benefit from:}

- fast, convenient online submission

- thorough peer review by experienced researchers in your field

- rapid publication on acceptance

- support for research data, including large and complex data types

- gold Open Access which fosters wider collaboration and increased citations

- maximum visibility for your research: over $100 \mathrm{M}$ website views per year

At BMC, research is always in progress.

Learn more biomedcentral.com/submissions 